\title{
sciendo
}

\section{Digital transformation trends reshaping companies}

\author{
Florina PÎNZARU \\ Faculty of Management, National University of Political Studies and Public Administration \\ (SNSPA), Bucharest, Romania \\ florina.pinzaru@facultateademanagement.ro
}

PICBE | 635

Alexandra ZBUCHEA

Faculty of Management, National University of Political Studies and Public Administration

(SNSPA), Bucharest, Romania

alexandra.zbuchea@facultateademanagement.ro

\begin{abstract}
Alexandra VIȚELAR
Faculty of Management, National University of Political Studies and Public Administration

(SNSPA), Bucharest, Romania

alexandra.vitelar@facultateademanagement.ro
\end{abstract}

\begin{abstract}
Nowadays, the ubiquity of the digital technology and the transformation it brings both within the societies and economies around the globe has become a well-accepted fact. For business is no longer a matter of whether or not to incorporate technology in their daily activity, but a matter how to change their way of approaching, and doing when adapting to digital. The digital transformation has enabled the emergence of new business models, as well as many other changes when it comes to satisfying the customer's needs and expectations, by creating opportunities for value and sustainability. The present paper highlights all these aspects, emphasizing on how businesses can think about the digital transformation to achieve the highest benefits and create competitive advantage.
\end{abstract}

Keywords: digital transformation, business optimization, digital imperative, digital business processes

\section{Introduction}

The fast-developing pace of economy based on digital technology, or what we call today the digital economy, is starting to reshape the business environment, compelling companies to reconfigure their business models, their processes or their strategies in one way or the other. One important aspect is the business-university alliance (Dima AM., et al., 2017). Understanding and optimizing the business processes in this new context has, therefore, become one of the main concerns of managers across all industries: in a technology driven economy, executives should be aware that digital technology can improve their businesses' performance, increasing productivity (Tapscott, 2015) while delivering better value to customers (Ganguly, 2015). 
Trying to understand the main digital factors that influence companies nowadays, our paper proceeds as follows: first, the digitization culture and technologies that enable it are presented. Secondly, we look at how the digital technologies impact the business models, and business performance. Then we investigate the latest trends, depicting some effects of the present wave of digitization. Finally, the conclusion with some recommendations are given.

\section{Understanding digital world - challenges and pitfalls of the digital change}

The digital transformation started some time ago, however the debate of the impact of digitization has upon economies and societies on all levels is still ongoing. For this reason, we analyze and structure digitization within two major approaches. First of all, we look at the digital technologies that shape our world today, and while analyzing the literature in this respect we identified the most prominent technologies associated with digitization: big data, cloud computing, digital platforms, Internet of things, and artificial intelligence (Schmidt, et al., 2016; Tapscott, 2015; McAfee \& Brynjolfsson, 2012). These technologies are employed by companies in order to deliver enhanced products or services by using the appropriate instruments, within financial stability (Dima\&Vasilache, 2016). This process, more often than not, comes along with a series of organizational changes: form process optimization, whit the aim of achieving higher revenues and cut back on costs. This brings us to our second approach, where we look at digitalization of businesses. In this respect, we look at the impact of the digital environment upon the structure and operations of companies. These approaches in our opinion will offer an insight in the understanding of decisions and strategies under the digital imperative. (McAfee \& Brynjolfsson, 2012)

Are we prepared for what is to come? Have we taken the necessary steps to maintain our business success? Here are just two of the many questions executives ought to think about. Change has become word-of-the-day for many organizational cultures, but according to recent studies (Bughin, LaBerge, \& Mellbye, 2017) the process of digitization is only at its beginning and its impact, although considerable, is far from complete.

The digitization is disrupting industry after industry and the pressure to plan for strategic innovation and technology incorporation in the company's day-to-day activity is high, enabled by the rapid spread of digital and mobile technologies (Ruggieri, R., ET AL., 2018). Nevertheless, rushing things, and not understanding what needs to change, or in other words changing for the sake of it, just because it's the new mantra of every other big global company, often leads to big flops. A McKinsey survey (2013) on over 2.000 executives reports that the companies with the highest revenue and earnings growth led the disruption or were fast followers, however these high revenues also came with high-risk rates, as companies gambled on innovative products, digital processes, and even entirely new business models, and the use of digital technologies is vital for the cost reduction and business optimization, as well. 
Up until this point we tried to show that, indeed, the digital technologies become more and more relevant for the success of companies, and there are many studies and survey that support this fact (Bollard, Larrea, Singla, \& Sood, 2018; Bughin, LaBerge, \& Mellbye, 2017; McKinsey, 2013), but now we want to focus our attention upon what kind of technologies and disruptive innovations shape our world. Nowadays, technological breakthroughs are around almost at every corner: instant communication, e-commerce, global platforms for sharing ideas and social interaction represent a comfortable reality. Due to the digitization process, the dynamics in many industries change, while new markets are proliferating, value chains are breaking up, and profit pools are shifting (Mckinsey, 2015).

\section{Digitization: the reshaping businesses}

In the new economy, companies must rethink their internal organization and culture, and implicitly their business models, in order to gain a competitive advantage (Anderson \& Irving Wladawsky -Berger, 2016; Brătianu, 2017). However, any digital transformation is not a game of chance, as it requires serious commitment and in the same time bold, sometimes risky, decision-taking. Therefore, a key role in any kind of transformation is played by the senior executive, whose vision and leadership can make the difference between a successful story, or a failure (Meffert, 2017).

Nevertheless, the pressure put on executives is increasingly high, due to the nature of technological advances nowadays. The dizzying pace of technological change and the frequent improvements in computing power has also led to the plummeting cost of advanced technologies, and this "means that the world around us is becoming ever more connected. In 2005 , there were just 500 million devices connected to the Internet; today there are 8 billion. By 2030, it's estimated that there will be 1 trillion." (World Economic Forum, 2016, p. 6). This shows us that the race for digital transformation is on. In the same report of the World Economic Forum (2016) the key elements that give digital companies an edge in this competitive global environment have been identified as follows: firstly, it is the culture of the company that enables companies to strive for new and leaner business models, then it is the strategy and the way of operating, enabling companies, once again, to aim for agile business processes, connected platforms, analytics and collaboration capabilities that enhance the productivity of the firm (ibidem, p. 9).

The dynamic and interconnected business environment, reshaped by technological changes, has just begun to impact companies, concerned also to social responsibility (Dima, Vasilache, 2013). We will continue to see its effects in the years to come, as business models are being redefined, while competitive strategic decisions are being made. Companies should take a structured and systematic approach when investigating the technological advances, while carefully considering how the digital can enable better products / services, as well as innovative business models and platforms (Parmar, Mackenize, Cohn, \& Gann, 2014). 


\section{Methodology}

Our study focuses provides a qualitative approach, focusing on a content analysis of periodical articles with global top executives. In this sense, we analyzed 10 interviews with CEOs (see Table 1) in several world-renowned business periodicals (Harvard Business Review, Mckinsey Quarterly, Forbes, Bloomberg Businessweek).

Table 1. CEOs' interviews analysed on the digitization of companies

\begin{tabular}{|c|c|c|c|}
\hline No & Name & Position / Company & Source \\
\hline 1. & Pablo Isla & CEO Inditex & $\begin{array}{l}\text { Isla, P. (2017, November-December). 2017's } \\
\text { Top-Performing CEO on Getting Product Right. } \\
\text { (D. McGinn, Interviewer) HBR. }\end{array}$ \\
\hline 2. & Virginia Rommetty & CEO IMB & $\begin{array}{l}\text { Rometty, V. (2017, July-August). "Don't Try to } \\
\text { Protect the Past". (A. Ignatius, Interviewer) HBR. }\end{array}$ \\
\hline 3. & Doug McMillon & CEO Walmart & $\begin{array}{l}\text { McMillon, D. (2017, March-April). We need } \\
\text { people to lean into the furture. (A. Ignatius, } \\
\text { Interviewer) HBR. }\end{array}$ \\
\hline 4. & Alain Bejjani & $\begin{array}{l}\text { CEO of conglomerate } \\
\text { Majid Al Futtaim }\end{array}$ & $\begin{array}{l}\text { Bejjani, A. (2017, August). Reshaping 'retail- } \\
\text { tainment' in the Middle East and beyond. (P. } \\
\text { Breuer, \& G. D'Auria, Interviewers) Mckinsey. }\end{array}$ \\
\hline 5. & Tim Cook & CEO Apple & $\begin{array}{l}\text { Cook, T. (2017, June). Tim Cook on Donald } \\
\text { Trump, the HomePod, and the Legacy of Steve } \\
\text { Jobs. (M. Murphy, Interviewer) Bloomberg } \\
\text { Businessweek. }\end{array}$ \\
\hline 6. & Jack Dorsey & CEO Twitter & $\begin{array}{l}\text { Dorsey, J. (2016, March). The Future of Twitter: } \\
\text { Q\&A with Jack Dorsey. An in-depth conversation } \\
\text { on } 10 \text { years of tweeting, the importance of live } \\
\text { media, and "the puddle.". (S. Frier, F. Gillette, \& } \\
\text { B. Stone, Interviewers) Bloomberg } \\
\text { Businessweek. }\end{array}$ \\
\hline 7. & Hikmet Ersek & $\begin{array}{l}\text { CEO Western Union } \\
\text { Holdings }\end{array}$ & $\begin{array}{l}\text { Ersek, H. (2018, January). Working across many } \\
\text { cultures at Western Union. (L. Davison, } \\
\text { Interviewer) Mckinsey Quarterly. }\end{array}$ \\
\hline 8. & Elmar Degenhart & CEO Continental & $\begin{array}{l}\text { Degenhart, E. (2016, May). Interview: } \\
\text { Continental CEO Elmar Degenhart On Charting } \\
\text { The Company's Future In Connected Mobility. } \\
\text { (D. Newcomb , Interviewer) Forbes. }\end{array}$ \\
\hline 9. & Ian Siegel & CEO ZipRecruiter & $\begin{array}{l}\text { Siegel, I. (2017, October). How AI Aids Small } \\
\text { Business Hiring: An Interview With } \\
\text { ZipRecruiter's CEO. (E. MacBride, Interviewer) } \\
\text { Forbes. }\end{array}$ \\
\hline 10. & Roelof Joosten & $\begin{array}{l}\text { CEO Royal Friesland } \\
\text { Campina }\end{array}$ & $\begin{array}{l}\text { Joosten, R. (2016, November). 'Either play or } \\
\text { shut up': An interview with Friesland Campina's } \\
\text { CEO. (D. Kuijpers , \& M. van Rooijen, } \\
\text { Interviewers) McKinsey Quarterly. }\end{array}$ \\
\hline
\end{tabular}

\section{Source: authors' analysis.}


The grid analysis of the content analysis was structured on five dimensions, based upon Gill \& VanBoskirk (2016, p. 3) and Anand \& Barsoux (2017, p. 83), as follows:

1) Culture - the company's approach to digitally driven innovation, and how it empowers employees with digital technology;

2) Technology - a company's use and adoption of emerging technologies, by PICBE | 639 reconfiguring the operating model;

3) Agility - how aligned a company is to support a digital strategy, by reconfiguring business processes;

4) Customer focus - how well a company uses customer and business data to measure success and adapt strategy, by tailoring solutions to user problems and reconfiguring the customer experience;

5) 5) Sustainability - become greener and more socially responsible by reconfiguring resources.

This study, therefore, focuses on identifying the main trends, enablers and blockers, of the digitization of companies, as perceived by top executives.

\section{Findings: understanding trends of the digitization of businesses}

Our analysis revealed the following five trends regarding the digitization of companies, as perceived by CEOs: 1) the balance between digital and human touch; 2) the mandatory digital transformation of businesses; 3 ) capturing value from the digital strategies; 4) the increasing importance of the customer journey in the digital age; 5) creating a sustainable future. We will present them furthermore.

\section{The long and winding road: balance digital \& the human touch}

The first dimension - culture - revealed the fact that it is important for companies to understand the needs of the employees and invest in their well-being and growth. The CEO of Apple, Tim Cook, point out that: "When you care about people's happiness and productivity, you give them what brings out the best in them and their creativity. (...) I think this megatrend is true in every country in the world, not just the United States. It leverages things that we're great at as a company. I think there can be dramatic growth for us." (Cook, 2017). In the same time, empowering employees is also crucial for companies, especially in the age where digital technologies are replacing many of the decision taking within companies. In this sense, Pablo Isla, CEO of Inditex, reveals that: "We make deliveries twice a week to every store. We use technology and algorithms that propose what garments to stock, but the store manager can change the order, because we want the store manager to feel like the owner of the product. It's a combination of technology and human touch." (Isla, 2017).

Thus, in a digitized world, one should not lose sight of the fact that the human touch is mandatory for the success and productivity of the company. The satisfaction of employees is important for companies, all the while adapting to the new ways of working and the new capabilities of their employees. Alain Bejjani, CEO of Majid Al Futtaim Group, the leading 
developer and operator of shopping malls across the Middle East, Africa, and Central Asia, points out the importance of the workforce and attracting top talent, but in order to attract the best talents, a company needs first to: "instill an open and learning mind-set in our organization. We need to continuously reinforce ourselves as an organization where talented, ambitious people can thrive. This is very difficult to get right and to sustain." (Bejjani, 2017).

In the same vein, the top executive of Friesland Campina, Roelof Joosten, reveals that: "Talent management is critical." (Joosten, 2016).

Companies can significantly benefit by implementing digital innovations as a response to the challenges that the company is facing. When discussing the what is the right strategic path, Virginia Rommetty, the CEO of IMB, states that "(...) the core businesses are not necessarily in growth markets. So we need to continually reinvent them. One example is our Global Business Services. We've been transitioning to digital, but it takes time, because it's a people business." (Rometty, 2017)

Therefore, companies have to not only invest in digital technologies, such as big data analytics, of AI, but also value their employees. New technologies can lead to increased productivity, but then again so do happy \& satisfied employees. This aspect increasingly becomes more important, as we are moving towards a Generation Y-heavy workforce.

\section{The future is digital}

Our second dimension, technology - reveals that companies do not really have a choice in the matter. "Change, transformation and adjustment have become the words of the day when it comes to businesses. I really believe the company has in its DNA the ability to change", says Virginia Rometty. And change is something all companies should consider as technology becomes an integral part of our lives. In this sense, the CEO of Majid Al Futtaim Group, highlights very interestingly the importance of technology: "Technology in our company was always perceived as an enabler yet was never fully integrated into everything we do. We've now established our School of Analytics \& Technology, with a curriculum that spans everyone in the company - from CEOs to frontline workers. I believe we are one of the few companies globally to have invested in analytical and digital capability building to such an extent." (Bejjani, 2017). Therefore, investing in digital capabilities and investing in digital technologies is a practice for many leading companies. The CEO of Twitter seems also very conscientious of the necessity of the digital technologies and their impact of the world, as Twitter is a social platform that enabled these kinds of transformations. Nevertheless, as he points out, it is important to continue to develop in this sense: "I think we can continue to augment reality in a very interesting way, in that it provides a conversation around anything that's happening in the world." (Dorsey, 2016).

The use and adoption of technologies becomes a central part of the operating models of any companies. The CEO of Continental, Elmar Degenhart, is confident that the future will be shaped by the smart technologies, especially in the automotive industry, and in this sense, he is already preparing his company, by creating an entirely new ITS (Intelligent 
Transportation Systems) business unit: "ITS is a completely different business model and the ITS business unit has the freedom to do things differently than the rest of the organization." (Degenhart, 2016). Technology pervades all industry sectors, and as the CEO of Majid Al Futtaim Group points out, technology is the currency of the future: "We see technology as the currency of the future. And we're working on establishing an online presence for our brands that will be as prominent as our offline presence, in particular, for our grocery retail business." (Bejjani, 2017). And adapting to the challenges and trends will be critical for the success of any business.

\section{Here, there and everywhere: capturing value from the digital strategy}

Our third dimension, agility - how aligned a company is to support digital strategy, by reconfiguring business processes, revealed that although not all companies are yet ready to fully incorporate new technologies, their efforts do include this aspect. While planning, companies should take under consideration the opportunities the digitization process brings. In this vein, the CEO of the Continental company points out: "We believe our opportunities in the service sector are a purely software-related business, compared to our established business model, which is hardware-based." (Degenhart, 2016). In the same vein, Bejjani states: "Our overarching strategic thrust is to continue to be fit for purpose. That means we need to transform ourselves from a largely brick-and-mortar business into a technologyfueled enterprise." (Bejjani, 2017). We see here two main ideas that focus upon formulating a business strategy that incorporates new technologies, and the transformation of companies from traditional ones to technological ones.

A bit more reserved, but still following the same line of thought, Doug McMillon, the CEO of the biggest US retailer, Walmart, states: "E-commerce and going digital are definitely near the top of our list. (...) Our goal is to be able to serve our future customers. To do that, we need to build strong and capable e-commerce business, - but also to strengthen what we're doing in stores." (McMillon, 2017). The strategy for Walmart does not only focus on developing e-commerce, but also focus on the customer's needs while strengthening their present strategy.

Having a clear focus is essential to any strategy building, may it be digital or not. Virginia Rometty (IBM) points this out: "First, you need to be clear about what you are transforming to. For us, it's all about data, and we have a very clear view of what our enterprise clients will need." (Rometty, 2017). However, this having a clear vision as a leader, can also bring you to developing entirely new business models, that respond to today's needs. In this sense, Ian Siegel, ZipRecruiter's CEO, points out that artificial intelligence technologies have a great impact on the HR sector, as he points out that: "Computers are better at predicting and finding candidates you like than you are." (Siegel, 2017).

In the struggle for efficient responses, adjustments and transformations to an increasingly digitized world, companies should take under consideration the impact and evolution of digitization in their industries as well as the impact it has upon their 
productivity and performance. The huge pressure put upon the CEOs shoulders is to instill the right vision and formulate the right integrated strategy to keep up with the competition. A common denominator in the analyzed interviews is also the focus CEOs place upon responding to the present and future customer's needs.

\section{Change is in the air: customers journeys become central}

Our fourth dimension - customer focus - looked at how well a company uses customer and business data to measure success and adapt strategy, by tailoring solutions to user problems and reconfiguring the customer experience. This aspect is near the top of the CEOs concerns. From finding the right products and services that match the customer needs, to listening to the customer's voice and understanding them - all CEOs, in one way or the other, mentioned the importance of a customized experience for their clients.

On the other hand, customers are reshaping the business landscape, as their preferences shift towards a technology- embedded experience. Alain Bejjani states: "The most exciting global trend affecting all of our businesses is the shift in consumer focus from product to experience. (...) we have turned our malls into social hubs and true "retail-tainment" destinations." (Bejjani, 2017).

Scholars also point out that that nowadays, along with digitization, customer preferences have changed "expecting that companies must provide best quality, green products, fast, at lowest price, with best service, and ensuring social responsibility - to name a few (Tapscott, 2015, p. 19). In this sense, companies try to do their best to meet their requirements. Let's take the example of Apple, their focus is to provide an entirely different, integrated experience for the consumer: "Our thing is to be the best and to give the user something that really makes a difference in their lives." (Cook, 2017)

Therefore, not only companies change, but also the customers. As Castells (2010) reveals, because of the technological changes occurring nowadays, we have entered a pattern of social interaction and social organization that is purely cultural. "This is why information is the key ingredient of our social organization and why flows of messages and images between networks constitute the basic thread of our social structure." (Castelles, 2010, p. 506). The CEO of Continental, Hikmet Ersek, in respect with the customer voice and the interconnected world in which we live, frames it firmly: "Many people say the voice of the CEO is very powerful. I don't think so. The voice of the customer has more power." (Degenhart, 2016).

\section{Creating a sustainable future}

Our fifth dimension - sustainability - focused on the company's efforts to become greener and more socially responsible by reconfiguring resources. Customers are more connected than ever before, in the same time they are more aware of the business practices of big companies and their impact on the environment. And just as Tapscott (2015) points out success in the new digital economy is dependent upon the social model for innovation, 
interdependence, sustainability and integrity. In this sense, leading companies have understood the trend and concentrate their efforts on this area.

In this sense, Friesland Campina mission is to promote as sustainable business by reconfiguring their resources. Their top executive highlights that the company is focused on sustainability, "which is one of our most important areas of focus." (Joosten, 2016). In the same time, other companies, from different business sectors, have a similar approach, for example Pablo Isla, the CEO of Inditex, states: "We have public commitment that all of our stores will be eco-efficient in the year 2020. That means they will use 40\% less water and 20\% less energy and that all materials will be environmentally certified. Today $70 \%$ of our stores meet that standard." (Isla, 2017).

The digital economy brings forth new business processes, and operating models that are lean, green and sustainable. While focusing on greener operating models, companies aim at creating a stellar reputation. Nevertheless, most companies take under consideration that by creating a sustainable business they can also create substantial value. In this case, companies can adopt new operating models. For example, Hikmet Ersek (CEO of Continental) reveals that they are developing a system, similar to the SixSigma, called the WU Way: "a kind of lean-management process-optimization environment, a disciplined approach based on the voice of the customer that can help this multicultural organization increase the discipline it needs." (Ersek, 2018).

Our study indicates that there are a number of things that the top executives have on their mind when it comes to the digitization process. Firstly, it is highly important to acknowledge the importance of the digital technologies and their impact on performance and productivity, but it is equally important to keep sight of the human component. Another significant aspect to keep in mind is the increased customer empowerment in an increasingly digital world through social networks, communities and other new available technologies. Hence companies should identify the evolving needs and expectation of their customers and tailor their products and services accordingly. Setting clear goals, and making use of available data and technologies is mandatory in the digital world. Innovating the business model, the services or products a business has to offer should not be taken lightly, nor hastily. Therefore, while keeping up with the latest trends and technology may be cool, the number one aspect to take under consideration is to have a clear vision of who you are as a company and what you want to transform into. Only then, can a company really make a difference and make an impact upon people's lives.

\section{Conclusions and recommendations}

The pace of technology change will probably accelerate in the years to come, and its impact upon the business environment will deepen. Hence, companies must evolve form a traditional model, to a digital technology-driven one, and just like in the case of all evolutionary process the survival of the fittest will mean that some companies will be able to unlock the benefits of the digital technologies, while other companies will fail. Dealing 
with disruption may bring major challenges, and as Bughin, Chui, \& Manyikav (2010) point out that "organizations should incorporate an understanding of the trends into their strategic thinking to help identify new market opportunities, invent new ways of doing business, and compete with an ever-growing number of innovative rivals".

Digitization has an impact throughout all of the company - from the workflows, to the business processes and operations. In this sense, technology is a catalyst for business transformation. Unfortunately for companies and their top executives there is no clear recipe for success, but rather a trial and error learning process. The recommendations in this aspect, have been highlighted in the analyzed interviews and literature review: firstly, while digital transformation is on all the agendas of the top companies, it is the CEO the one who points the direction and the pace of the transformation. Having a clear vision and setting achievable goals is critical in this aspect. Secondly, the digital transformation reframes everything about how products are made, sold, delivered, and it makes it mandatory for companies to rethink how they execute, what new business processes, operations or models they bring forward. Never losing sight of the human aspect of the business is critical in this respect. Thirdly, the digital transformation also led to customers becoming an important link of the company's ecosystem, and, therefore, delivering individualized experiences and making a difference through the products and services a company has to offer is essential. Finally, companies should also take into account that customer demands nowadays also include developing a business for the future, this means that companies should take into consideration the creation of sustainable capabilities while embarking in the digital transformation.

\section{References}

Bejjani, A. (2017, August). Reshaping 'retail-tainment' in the Middle East and beyond. (P. Breuer, \& G. D'Auria, Interviewers) Mckinsey.

Bollard, A., Larrea, E., Singla, A., \& Sood, R. (2018, January). The next-generation for the digital world. Digital McKinsey, pp. 22-29.

Brătianu, C. (2017). The Crazy New World of the Sharing Economy. In M. E. Vătămănescu, \& F. M. Pînzaru, Knowledge Management in the Sharing Economy. Cross-Sectoral Insights into the Future of Competitive Advantage (pp. 3-18). Cham: Springer.

Bughin, J., Chui, M., \& Manyika, J. (2010, August). Clouds, big data, and smart assets: Ten techenabled business trends to watch. McKinsey Quarterly. Retrieved February 2018, from https://www.mckinsey.com/industries/high-tech/our-insights/clouds-bigdata-and-smart-assets-ten-tech-enabled-business-trends-to-watch

Bughin, J., LaBerge, L., \& Mellbye, A. (2017, February). The case for digital reinvention. McKinsey Quarterly. Retrieved January 2018, from https://www.mckinsey.com/business-functions/digital-mckinsey/our-insights/thecase-for-digital-reinvention

Castells, M. (2010). The Rise of the Network Society. Cambridge: Blackwell Publishers, Inc. 
Cook, T. (2017, June). Tim Cook on Donald Trump, the HomePod, and the Legacy of Steve Jobs. (M. Murphy, Interviewer) Bloomberg Businessweek.

Degenhart, E. (2016, May). Interview: Continental CEO Elmar Degenhart On Charting The Company's Future In Connected Mobility. (D. Newcomb, Interviewer) Forbes. Retrieved January 2018, from https://www.forbes.com/sites/dougnewcomb/2016/05/31/interview-continentalceo-elmar-degenhart-on-charting-the-companys-future-in-connectedmobility/\#6409c0fa2b22

Dima, A., Hadad, S., Luchian, I., (2017), "Review on the dimensions of business-university alliances", Proceedings of the 11th International Conference on Business Excellence, pp. 64-73, DOI: $10.1515 /$ picbe-2017-0007.

Dima, MA, Vasilache, S. (2016). Credit Risk modeling for Companies Default Prediction using Neural Networks, Journal for Economic Forecasting, Institute for Economic Forecasting, vol. 21(3), pages 127-143, September.

Dima, MA, Vasilache, S. (2013), An Analysis on the Link Between Emerging Markets MNEs' Reputation and Corporate Social Responsibility, in Liam Leonard, Maria Alejandra Gonzalez-Perez (ed.) Principles and Strategies to Balance Ethical, Social and Environmental Concerns with Corporate Requirements (Advances in Sustainability and Environmental Justice, Volume 12) Emerald Group Publishing Limited, pp.51 66

Dorsey, J. (2016, March). The Future of Twitter: Q\&A with Jack Dorsey. An in-depth conversation on 10 years of tweeting, the importance of live media, and "the puddle.". (S. Frier, F. Gillette, \& B. Stone, Interviewers) Bloomberg Businessweek.

Ersek, H. (2018, January). Working across many cultures at Western Union. (L. Davison, Interviewer) Mckinsey Quarterly.

European Commission. (2017, May 10). Policies, information and services. Digital Single Market. Retrieved from ec.europa.eu: https://ec.europa.eu/digital-singlemarket/en/news/digital-single-market-mid-term-review

Gill, M., \& VanBoskirk, S. (2016). The Digital Maturity Model 4.O. Benchmarks: Digital Business Transformation Playbook. Cambridge: Forrester research, inc.

Isla, P. (2017, November-December). 2017's Top-Performing CEO on Getting Product Right. (D. McGinn, Interviewer) HBR.

Joosten, R. (2016, November). 'Either play or shut up': An interview with FrieslandCampina's CEO. (D. Kuijpers , \& M. van Rooijen, Interviewers) McKinsey Quarterly.

Loebbecke, C., \& Picot, A. (2015). Reflections on societal and business model transformation arising from digitization and big data analytics: A research agenda. J. Strateg. Inform. Syst. doi:http://dx.doi.org/10.1016/j.jsis.2015.08.002

McAfee, A., \& Brynjolfsson, E. (2012, October). Big data: the management revolution. Harvard Business Review, 90(10), pp. 60-98.

McKinsey. (2013). Bullish on digital: McKinsey Global Survey results. Digital McKinsey. McKinsey \& Company. Retrieved February 2018, from 
https://www.mckinsey.com/business-functions/digital-mckinsey/ourinsights/bullish-on-digital-mckinsey-global-survey-results

McKinsey. (2015). Digital America: A tale of the haves and have-mores. McKinsey Global Institute. Retrieved February 2018, from https://www.mckinsey.com/industries/high-tech/our-insights/digital-america-atale-of-the-haves-and-have-mores

PICBE $\mid 646$

McMillon, D. (2017, March-April). We need people to lean into the furture. (A. Ignatius, Interviewer) HBR.

Meffert, J. (2017, August). How to make sure your digital transformation succeeds. (M. Hattrup-Silberberg, Interviewer) McKinsey\&Company. Retrieved February 2018, from https://www.mckinsey.com/business-functions/digital-mckinsey/ourinsights/how-to-make-sure-your-digital-transformation-succeeds

Parmar, R., Mackenize, I., Cohn, D., \& Gann, D. (2014, January-February). The New Patterns of Innovation. HBR. Retrieved February 2018, from https://hbr.org/2014/01/thenew-patterns-of-innovation

Rometty, V. (2017, July-August). "Don't Try to Protect the Past". (A. Ignatius, Interviewer) HBR.

Ruggieri, R., Savastano, M., Scalingi, A., Bala, D., and D’Ascenzo, F. (2018), “The impact of Digital Platforms on Business Models: an empirical investigation on innovative startups", Management \& Marketing. Challenges for the Knowledge Society, Vol., 13, No 4, pp. 1210-1225. DOI: 10.2478/mmcks-2018-0032.

Shirky, C. (2008). Here Comes Everybody: How Change Happens when People Come together. London: Penguin Books.

Siegel, I. (2017, October). How AI Aids Small Business Hiring: An Interview With ZipRecruiter's CEO. (E. MacBride, Interviewer) Forbes.

Tapscott, D. (2015). The Digital Economy. Rethinking Promise And Peril In The Age Of Networked Intellingence (20th anniversary edition ed.). New York: McGraw-Hill Education.

World Economic Forum. (2016). World Economic Forum White Paper. Digital Transformation of Industries: Digital Entreprise. In collaboration with Accenture. Retrieved February 2018, from http://reports.weforum.org/digital-transformation/wpcontent/blogs.dir/94/mp/files/pages/files/digital-enterprise-narrative-finaljanuary-2016.pdf 